\title{
Spectral characteristics and DFT Study of vanadyl octaethylporphyrin complex
}

\author{
Hamza El Hadki 1,*, Mohammed Salah ${ }^{2}$, Abdallah Zrineh ${ }^{1}$, Khadija Marakchi ${ }^{1}$, Hassna Abou \\ El Makarim ${ }^{1}$, Najia Komiha ${ }^{1}$ and Oum Keltoum Kabbaj ${ }^{1}$ \\ ${ }^{1}$ CERNE2D: Laboratory of Spectroscopy, Molecular Modeling, Materials, Nanomaterials, Water and \\ Environment (LS3MN2E) - Faculty of Sciences - University Mohammed V, Rabat - Morocco \\ ${ }^{2}$ Molecular Modeling and Spectroscopy Research Team (MMSRT), Faculty of Sciences University Chouaïb \\ Doukkali - El Jadida - Morocco
}

\begin{abstract}
The chemistry of vanadyl porphyrins has been explored using vanadyl octaethylporphyrin as a substance in petroleum porphyrins, crude oils and bitumen. The structural, electronic, thermodynamic, spectroscopic properties are described. The geometry's optimization of this molecule was done by Density Functional Theory (DFT) using the hybrid Beck three-parameter hybrid functional combined with Lee-Yang-Parr correlation functional (B3LYP) and 6-31G(d) standard basis set. All calculations have been made in the gas phase and in different solvents: benzene, benzonitrile, tetrachloromethane and chloroform. The calculated infrared spectrum was compared with experimental spectroscopic data, and the vibrational assignment was provided. An electron density analysis in terms of natural bond orbitals was conducted to determine the nature of the bonds between the vanadium and nitrogen atoms. The spatial representation of the associated molecular orbitals helped to explain the formation of the V-N bonds and to interpret the chemical reactivity of the compound studied. The electrostatic potential was calculated in order to investigate the reaction properties of the molecule.
\end{abstract}

Keywords: vanadyl octaethylporphyrin; quantum chemical calculations; IR spectrum; electronic properties.

\section{Introduction}

The presence of metals in phosphates, mainly vanadium, is associated with adverse environmental influences ${ }^{1,2}$. The aims of this publication are to report the characterization of $\mathrm{VO}(\mathrm{II})$ adducts with octaethylporphyrin using quantum chemical calculations to determine the geometric and electronic structure of (OEP)VO. Quantum chemical parameters, such as the highest occupied and lowest unoccupied molecular orbital energy levels, ionization potential, atomic charges and electrondensity distribution, have been calculated at the B3LYP/6-31G(d) level of theory. In particular, reactive behavior of (OEP)VO has been investigated based on electro negativity, electron-donating ability and a fraction of an electron transferred from the molecule to the metal atom. The effect of benzonitrile, benzene, tetrachloromethane and chloroform as a solvent on the calculated parameters since reaction commonly occurs in the liquid phase has been considered.

\section{Computational methods}

All DFT calculations were carried out at the B3LY/6-31G(d) level which combined the exact

*Corresponding author : Hamza El Hadki

Email address : hamza.hadk@gmail.com

DOI: http://dx.doi.org/10.13171/mjc8219043008heh
Hartree-Fock exchange with Becke's three-parameter hybrid method (B3) ${ }^{3}$ and used Lee-Yang-Parr correlation function (LYP) ${ }^{4}$ to include the most important correlation effects. The version used was that implemented in the Gaussian09 program package ${ }^{5}$. The molecular structure of (OEP)VO was optimized without any constraint of symmetry. The optimized structural parameters were used in the vibrational frequency calculations to characterize the minimum energy structure. Natural bond orbital analyses (NBO) ${ }^{6}$ was performed on the B3LYP level. To study the reaction behavior of the system, the electrostatic potential ${ }^{7}$ of (OEP)VO was calculated by DFT method. In order to characterize the electronic population on each atomic center, Mulliken population analysis ${ }^{8}$ was carried out, and Self-consistent reaction field theory (SCRF) ${ }^{9}$ with Tomasi's polarized continuum model (PCM) was used to perform calculations in solution ${ }^{10}$. All the geometries of the calculated electronic structures were built and visualized using the graphical interface GaussView ${ }^{11}$. ChemDraw software was used to draw molecular structures.
Received February 12, 2019

Accepted April 112019

Published April 30, 2019 


\section{Results and Discussion}

\section{Geometry optimization}

DFT methods are known to describe correctly systems containing transition metals. This is why we have used it for the determination and analysis of the metalloporphyrin (OEP)VO at the B3LYP/6-31G (d) level. The visualization of the optimized geometric structure and the atomic labelling are shown in Figure 1. The fully optimized structure coordinate (xyz) in doublet spin state, as well as the geometrical parameters in the gas phase and in solution (benzene, benzonitrile, tetrachloromethane and chloroform), are listed in Tables 1 and 2. The equilibrium bond distances and angles are indicated respectively in angstroms and degrees.

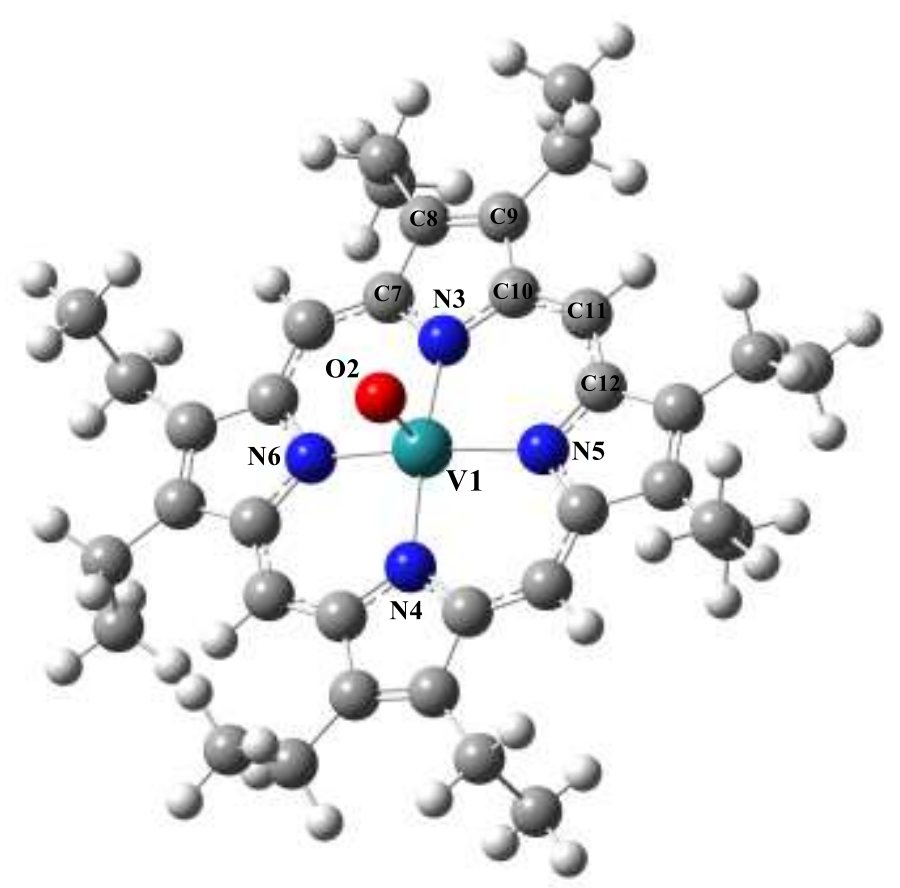

Figure 1. Optimized geometrical structure and atomic labelling of(OEP)VO

Table 1. The atomic coordinates of (OEP)VO.

\begin{tabular}{|c|c|c|c|c|c|c|c|c|}
\hline Atom & $\mathrm{x}$ & & $\mathrm{y}$ & $\mathrm{z}$ & Atom & $\mathrm{x}$ & $\mathrm{y}$ & $\mathrm{z}$ \\
\hline $\mathrm{C}_{1}$ & 4.20 & & -0.90 & 0.09 & $\mathrm{C}_{16}$ & 0.90 & 4.20 & 0.09 \\
\hline $\mathrm{C}_{2}$ & 3.70 & & -2.18 & 0.09 & $\mathrm{C}_{17}$ & 2.18 & 3.70 & 0.09 \\
\hline $\mathrm{C}_{3}$ & 2.26 & & -2.06 & 0.04 & $\mathrm{C}_{18}$ & 2.06 & 2.26 & 0.04 \\
\hline $\mathrm{C}_{4}$ & 1.38 & & -3.13 & 0.04 & $\mathrm{C}_{19}$ & 3.13 & 1.38 & 0.04 \\
\hline $\mathrm{C}_{5}$ & -0.01 & & -3.06 & 0.03 & $\mathrm{C}_{20}$ & 3.06 & -0.01 & 0.03 \\
\hline $\mathrm{C}_{6}$ & -0.90 & & -4.20 & 0.09 & $\mathrm{~N}_{21}$ & 1.89 & -0.73 & 0.00 \\
\hline $\mathrm{C}_{7}$ & -2.18 & & -3.70 & 0.09 & $\mathrm{~N}_{22}$ & -0.73 & -1.89 & 0.00 \\
\hline $\mathrm{C}_{8}$ & -2.06 & & -2.26 & 0.04 & $\mathrm{~N}_{23}$ & -1.89 & 0.73 & 0.00 \\
\hline $\mathrm{C}_{9}$ & -3.13 & & -1.38 & 0.04 & $\mathrm{~N}_{24}$ & 0.73 & 1.89 & 0.00 \\
\hline $\mathrm{C}_{10}$ & -3.06 & & 0.01 & 0.03 & $\mathrm{H}_{25}$ & 4.12 & 1.81 & 0.06 \\
\hline $\mathrm{C}_{11}$ & -4.20 & & 0.90 & 0.09 & $\mathrm{H}_{26}$ & 1.81 & -4.12 & 0.06 \\
\hline $\mathrm{C}_{12}$ & -3.70 & & 2.18 & 0.09 & $\mathrm{H}_{27}$ & -4.12 & -1.81 & 0.06 \\
\hline $\mathrm{C}_{13}$ & -2.26 & & 2.06 & 0.04 & $\mathrm{H}_{28}$ & -1.81 & 4.12 & 0.06 \\
\hline $\mathrm{C}_{14}$ & -1.38 & & 3.13 & 0.04 & $\mathrm{~V}_{85}$ & 0.00 & 0.00 & -0.54 \\
\hline $\mathrm{C}_{15}$ & 0.01 & & 3.06 & 0.03 & $\mathrm{O}_{86}$ & 0.00 & 0.00 & -2.11 \\
\hline
\end{tabular}


Table 2. Selected structural parameters of (OEP)VO.

\begin{tabular}{|c|c|c|c|c|c|}
\hline \multirow{2}{*}{ gas phase } & \multicolumn{4}{|c|}{ solvated phases } \\
\cline { 3 - 6 } & & $\mathrm{C}_{7} \mathrm{H}_{5} \mathrm{~N}$ & $\mathrm{CCl}_{4}$ & $\mathrm{CHCl}_{3}$ & $\mathrm{C}_{6} \mathrm{H}_{6}$ \\
\hline $\mathrm{V}-\mathrm{O}$ & 1.571 & 1.584 & 1.576 & 1.580 & 1.576 \\
\hline $\mathrm{V}-\mathrm{N}$ & 2.096 & 2.090 & 2.094 & 2.092 & 2.094 \\
\hline $\mathrm{C}_{7}-\mathrm{N}_{3}$ & 1.376 & 1.378 & 1.377 & 1.378 & 1.377 \\
\hline $\mathrm{C}_{8}-\mathrm{C}_{9}$ & 1.372 & 1.374 & 1.373 & 1.373 & 1.373 \\
\hline $\mathrm{C}_{7}-\mathrm{C}_{8}$ & 1.450 & 1.449 & 1.450 & 1.449 & 1.450 \\
\hline $\mathrm{C}_{10}-\mathrm{C}_{11}$ & 1.391 & 1.391 & 1.391 & 1.390 & 1.391 \\
\hline $\mathrm{N}-\mathrm{V}-\mathrm{N}$ & 86.2 & 86.4 & 86.3 & 86.3 & 86.3 \\
\hline $\mathrm{N}-\mathrm{V}-\mathrm{O}$ & 104.9 & 104.6 & 104.8 & 104.7 & 104.8 \\
\hline $\mathrm{C}_{9}-\mathrm{C}_{8}-\mathrm{C}_{7}$ & 106.5 & 106.5 & 106.5 & 106.5 & 106.5 \\
\hline $\mathrm{C}_{8}-\mathrm{C}_{7}-\mathrm{N}_{3}$ & 110.5 & 110.6 & 110.5 & 110.5 & 110.5 \\
\hline $\mathrm{C}_{7}-\mathrm{N}_{3}-\mathrm{C}_{10}$ & 105.9 & 105.8 & 105.9 & 105.8 & 105.9 \\
\hline $\mathrm{C}_{10}-\mathrm{C}_{11}-\mathrm{C}_{12}$ & 126.4 & 126.3 & 126.3 & 126.3 & 126.3 \\
\hline$\Delta\left(\mathrm{V}_{12}-\mathrm{P}_{4 \mathrm{~N}}\right)$ & 0.543 & 0.528 & 0.536 & 0.530 & 0.536 \\
\hline
\end{tabular}

$\Delta\left(\mathrm{V}-\mathrm{P}_{4 \mathrm{~N}}\right)$ : the distance between the $\mathrm{V}$ atom and the plane formed by the four nitrogen atoms.

The compound studied, of symmetry $\mathrm{C}_{4}$, presents for its equilibrium structure a pseudo-square pyramidal geometry where $\mathrm{V}$ (IV) is five coordinates. The pyrrole rings keep a near planar structure, and the deviation from planarity of the metal atom can be measured which is located above the plane of the four nitrogen atoms $\Delta\left(\mathrm{V}-\mathrm{P}_{4 \mathrm{~N}}\right)$ by an average of $0.54 \AA$. This distortion is certainly due to the great electronegativity of the oxygen atom in the vanadyl group and the open shell nature of the complex. distances and valence angles is respectively $0.013 \AA$ and $0.1^{\circ}$ in different phases. The $\mathrm{V}-\mathrm{O}$ bond distances obtained are comparable to the values of 1.582-1.625 $\AA$ registered in the literature ${ }^{12}$, and the latest DFT study at Becke-Perdew level which reported for V-N and $\mathrm{V}-\mathrm{O}$ bond distances $2.102 \AA$ and $1.597 \AA$ respectively ${ }^{13}$. The value of $\left(\mathrm{N}_{1} \mathrm{VN}_{3}\right)$ or $\left(\mathrm{N}_{2} \mathrm{VN}_{4}\right)$ and therefore the height of the pyramid depends on the $\mathrm{V}-\mathrm{N}$ bond length (Figure 2).

For the porphyrinic macrocycle ligand, the maximum difference between corresponding bond

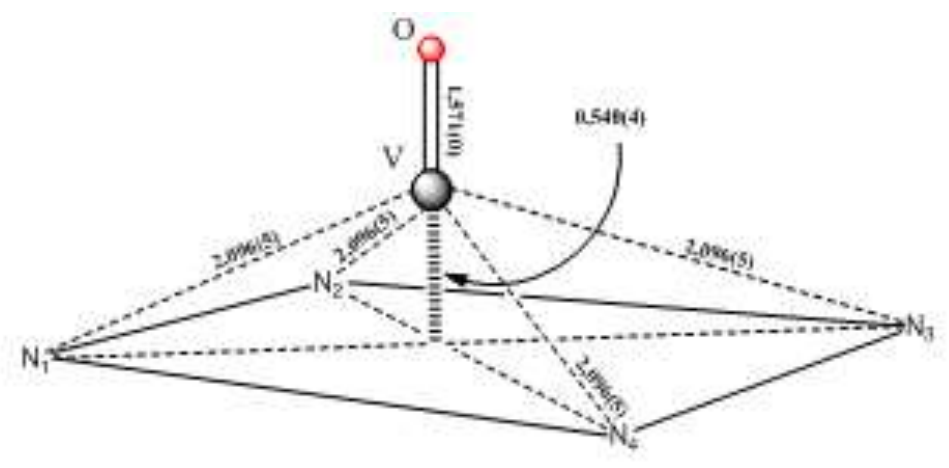

Figure 2. Side-view sketch of (OEP)VO showing the orientation of the vanadium and oxygen atoms in the gas phase

It can be seen that the DFT method produce structural parameters which well agreed with the experimental structure analyses reported for similar compounds ${ }^{14}$.

\section{Net atomic charges}

Quantum-chemical calculations provide the ability to calculate the net atomic charges (q), which are localized at the corresponding atoms as a result of the redistribution of the electrons in the molecule. Though they are not connected with physical properties and cannot be observed experimentally, they allow the understanding of the distribution of the electronic density in a system of connected atoms and predict some chemical properties of the molecules. The net atomic charges calculated by Mulliken are presented in Table 3. 
Table 3. Mulliken atomic charges of (OEP)VO.

\begin{tabular}{|c|c|c|c|c|c|}
\hline \multicolumn{6}{|c|}{$(\mathrm{OEP}) \mathrm{VO}$} \\
\hline & $\mathrm{Gaz}$ & $\mathrm{C}_{7} \mathrm{H}_{5} \mathrm{~N}$ & $\mathrm{CCl}_{4}$ & $\mathrm{CHCl}_{3}$ & $\mathrm{C}_{6} \mathrm{H}_{6}$ \\
\hline $\mathrm{N}_{3}$ & -0.78 & -0.78 & -0.78 & -0.78 & -0.78 \\
\hline $\mathrm{N}_{4}$ & -0.78 & -0.78 & -0.78 & -0.78 & -0.78 \\
\hline $\mathrm{N}_{5}$ & -0.78 & -0.78 & -0.78 & -0.78 & -0.78 \\
\hline $\mathrm{N}_{6}$ & -0.78 & -0.78 & -0.78 & -0.78 & -0.78 \\
\hline $\mathrm{V}_{1}$ & 1.22 & 1.20 & 1.21 & 1.21 & 1.21 \\
\hline $\mathrm{O}_{2}$ & -0.45 & -0.52 & -0.48 & -0.50 & -0.48 \\
\hline
\end{tabular}

The Mulliken's charge analysis shows that nitrogen and oxygen atoms exhibit their electronegative nature as expected. The analysis of the electron density distribution in terms of natural bond orbital's show that the electronic configuration of vanadium atom in (OEP)VO: [core] $4 \mathrm{~s}^{0.23} 3 \mathrm{~d}^{3.09} 4 \mathrm{p}^{0.5} 4 \mathrm{~d}^{0.01}$ varies from the configuration of $\mathrm{VO}^{2+}$ : [core] $4 \mathrm{~s}^{0.01} 3 \mathrm{~d}^{2.94} 4 \mathrm{p}^{0.02}$. The natural charge of the atom $\mathrm{V}$ in (OEP) VO is in the order of 1.20. Similarly, the four nitrogen atoms in (OEP)VO are equivalent and have the configurations: [core] $2 \mathrm{~s}^{1.35} 2 \mathrm{p}^{4.23} 3 \mathrm{p}^{0.01}$ with a natural charge of -0.56 that does not change by adding a solvent.
The NBO analysis allows the evaluation of the quality of the complex structure (OEP)VO by evaluating the number of electrons in our structure which is by $97.49 \%$ of natural Lewis-type.

The nature of the V-N bond could be explained by an orbital interaction analysis. We examined the donor-acceptor interactions between the vanadium atom and the four equivalent nitrogen atoms of the porphyrinic macrocycle.

In Table 4, the composition of the main interacting hybrid orbitals of vanadium and nitrogen was reported along with their population.

Table 4. Composition of selected interacting orbitals ( $\alpha$ and $\beta$ spin) of $\mathrm{V}$ and $\mathrm{N}$ atoms with their populations for (OEP)VO.

\begin{tabular}{|l|c|c|c|}
\hline \multicolumn{4}{|c|}{ Donation $\mathrm{N} \rightarrow \mathrm{VO}$} \\
\hline \multicolumn{1}{|c|}{$\mathrm{V}$} & population & \multicolumn{1}{|c|}{ orbital composition } & population \\
\hline \multicolumn{1}{|c|}{ orbital composition } & 5.623 & $0.66(2 \mathrm{~s})+0.75\left(2 \mathrm{p}_{\mathrm{x}}\right)+0.62\left(2 \mathrm{p}_{\mathrm{y}}\right)+0.72\left(2 \mathrm{p}_{\mathrm{z}}\right)$ & 2.768 \\
\hline $\begin{array}{l}0.12(4 \mathrm{~s})+0.63\left(3 \mathrm{~d}_{\mathrm{xy}}\right)+0.57\left(3 \mathrm{~d}_{\mathrm{x} 2-\mathrm{y} 2}\right) \\
+0.38\left(3 \mathrm{~d}_{\mathrm{z} 2}\right)\end{array}$ & 4.596 & $0.66(2 \mathrm{~s})+0.75\left(2 \mathrm{p}_{\mathrm{x}}\right)+0.62\left(2 \mathrm{p}_{\mathrm{y}}\right)+0.72\left(2 \mathrm{p}_{\mathrm{z}}\right)$ & 1.781 \\
\hline $\begin{array}{l}0.11(4 \mathrm{~s})+0.22\left(3 \mathrm{~d}_{\mathrm{xz}}\right) \\
0.22\left(3 \mathrm{~d}_{\mathrm{yz}}\right)+0.11\left(3 \mathrm{~d}_{\mathrm{x} 2-\mathrm{y} 2}\right)+0.33\left(3 \mathrm{~d}_{\mathrm{z} 2}\right)\end{array}$ & & & 1.0 \\
\hline
\end{tabular}

Table 5. Important delocalization interactions in the NBO.

\begin{tabular}{|c|c|c|c|c|}
\hline donor (i) & acceptor (j) & $\mathrm{E}(2)^{\mathrm{a}}$ & $E(j)-E(i)^{b}$ & $F(i, j)^{c}$ \\
\hline $\mathrm{LP}(1) \mathrm{N}$ & $\mathrm{LP}(2) \mathrm{V}$ & 12.75 & 0.35 & 0.087 \\
\hline $\mathrm{LP}(1) \mathrm{N}$ & $\mathrm{LP}^{*}(3) \mathrm{V}$ & 15.45 & 0.56 & 0.118 \\
\hline $\mathrm{LP}(1) \mathrm{N}$ & $L P *(4) \mathrm{V}$ & 2.70 & 0.66 & 0.055 \\
\hline $\mathrm{LP}(1) \mathrm{N}$ & $\mathrm{LP}^{*}(5) \mathrm{V}$ & 17.62 & 0.66 & 0.140 \\
\hline $\mathrm{LP}(1) \mathrm{N}$ & $\mathrm{LP}^{*}(6) \mathrm{V}$ & 3.16 & 0.59 & 0.056 \\
\hline $\mathrm{LP}(1) \mathrm{N}$ & $\mathrm{RY}^{*}(1) \mathrm{V}$ & 0.23 & 1.08 & 0.021 \\
\hline $\mathrm{LP}(1) \mathrm{N}$ & $\mathrm{RY} *(3) \mathrm{V}$ & 0.06 & 1.34 & 0.012 \\
\hline $\mathrm{LP}(1) \mathrm{N}$ & $\mathrm{RY}^{*}(4) \mathrm{V}$ & 0.39 & 1.34 & 0.031 \\
\hline $\mathrm{LP}(1) \mathrm{N}$ & $\mathrm{RY}^{*}(5) \mathrm{V}$ & 0.05 & 1.11 & 0.010 \\
\hline $\mathrm{LP}(1) \mathrm{N}$ & $\mathrm{RY}^{*}(6) \mathrm{V}$ & 0.31 & 1.94 & 0.033 \\
\hline $\mathrm{LP}(1) \mathrm{N}$ & RY*(13) V & 0.05 & 2.74 & 0.016 \\
\hline $\mathrm{LP}(1) \mathrm{N}$ & $\mathrm{RY} *(16) \mathrm{V}$ & 0.05 & 2.88 & 0.016 \\
\hline
\end{tabular}

${ }^{\mathrm{a}}$ second-order stabilisation energy. ${ }^{\mathrm{b}}$ difference in energy between the donor and acceptor NBOs. ${ }^{\mathrm{c}}$ off-diagonal NBO Fock matrix elements for NBO (i) and NBO (j). 
This analysis has shown that Rydberg orbitals do not interfere in the interaction of the four nitrogen atoms with vanadium since the coefficients associated with these orbitals are almost insignificant. The donation of the electrons will, therefore, be from the nitrogen atoms to the vanadyl ion $(\mathrm{VO})^{2+}$.

In Table 5, the energy of delocalization is expressed in $\mathrm{kcal} / \mathrm{mol}$; all the other values are in a.u. NBO donors are indicated as lone pairs (LP). The NBO orbitals are numbered when more than one is possible. NBO acceptors are presented as non-Lewis Rydberg orbitals $\left(\mathrm{RY}^{*}\right)$, lone pairs (LP) or (LP*).

The stability of the complex is mainly determined by the interaction energy between the occupied orbitals of the four nitrogen atoms and the vacant orbitals of vanadium by a direct donation.

According to the NBO analysis, the total donoracceptor interaction energy per one $\mathrm{V}-\mathrm{N}$ bond is 55 $\mathrm{kcal} / \mathrm{mol}$ (0.087 a.u.). This value is comparable for analogous compounds as CuOMP ${ }^{15}$ and SnOMP ${ }^{16}$.
The effects of this donation lead to a reduction in the central charge of the vanadyl ion compared to its formal value $(+2)$. In fact, for the isolated species $(\mathrm{VO})^{2+}$ and $(\mathrm{OEP})^{2-}$, the natural charge associated with the vanadium atom and the four nitrogen atoms are respectively 2.05 and -1.76 . For the (OEP)VO complex the values are 1.20 and -2.24 . These data indicate the existence of a charge transfer from the porphyrinic cycle to the vanadyl group, indicating the creation of $\mathrm{N} \rightarrow \mathrm{V}$ dative bonds.

\section{Molecular electrostatic potential analysis}

The molecular electrostatic potential is a property that the electrons and nuclei of a molecule generate an electrical potential at each point of the space and furnish a visualization to value the polarity of a molecule.

The electron density isosurface for (OEP)VO shown in Figure 3 reveals that the lone pair electrons are spherically distributed around the vanadyl group.

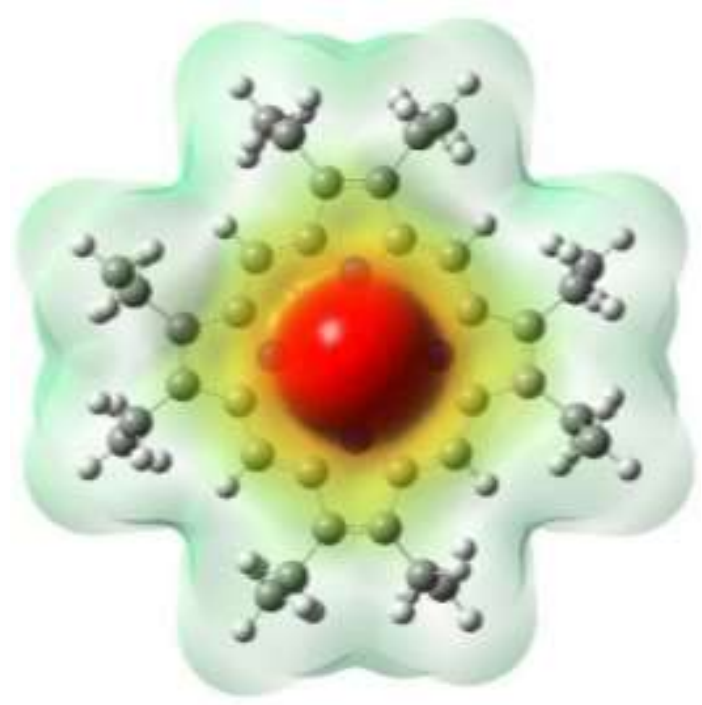

Figure 3. Molecular electrostatic potential mapped on the surface for (OEP)VO

The low electrostatic potential region (red zone), characterized by an abundance of electrons, is mainly associated with the oxygen atom of the vanadyl group; this is certainly due to the great electronegativity of this atom. The regions in the center of the macrocycle (deep green zone) correspond to a negative potential and thus to nucleophilic centers. This can, therefore, explain that the oxovanadium ion has a net positive charge inducing a negative charge on the porphyrin ligand explaining the attractive electrostatic interaction.

\section{Orbital analysis}

The metalloporphyrin studied is formed of a metal ion in the oxidation state $+\mathrm{II}$ and a porphyrin dianionic which can behave a dibasic molecule. This compound is formed by the interaction between the molecular orbitals HOMO of (OEP) ${ }^{2-}$ and LUMO of $(\mathrm{VO})^{2+}$ reported in the following Figure. It can be noted that in the xôy plane, the electron density of the dianion is located above the four nitrogen atoms and the vanadium ion intervenes with its $\mathrm{d}_{\mathrm{x}-\mathrm{y}}^{2}$ orbital inducing the formation of $\mathrm{V}-\mathrm{N}$ bonds. 


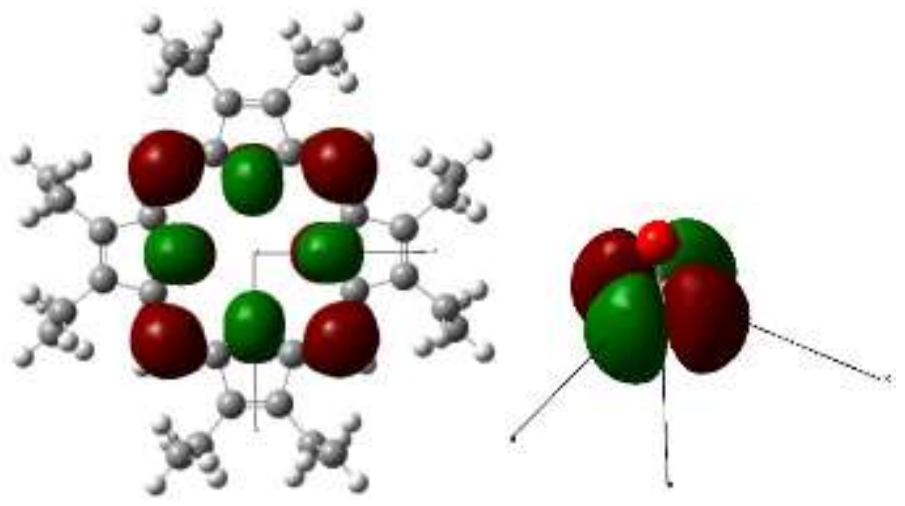

Figure 4. Molecular orbital representation:

Left: HOMO of $(\mathrm{OEP})^{2-}$; Right: LUMO of $(\mathrm{VO})^{2+}$ - isovalue of molecular density plot: 0.02

Subsequently, we investigated the molecular orbitals $(\mathrm{HOMO}-1 \rightarrow \mathrm{LUMO}+1)$ of the complex in the gaseous and solvated states. The representation of these is shown in Figure 5.

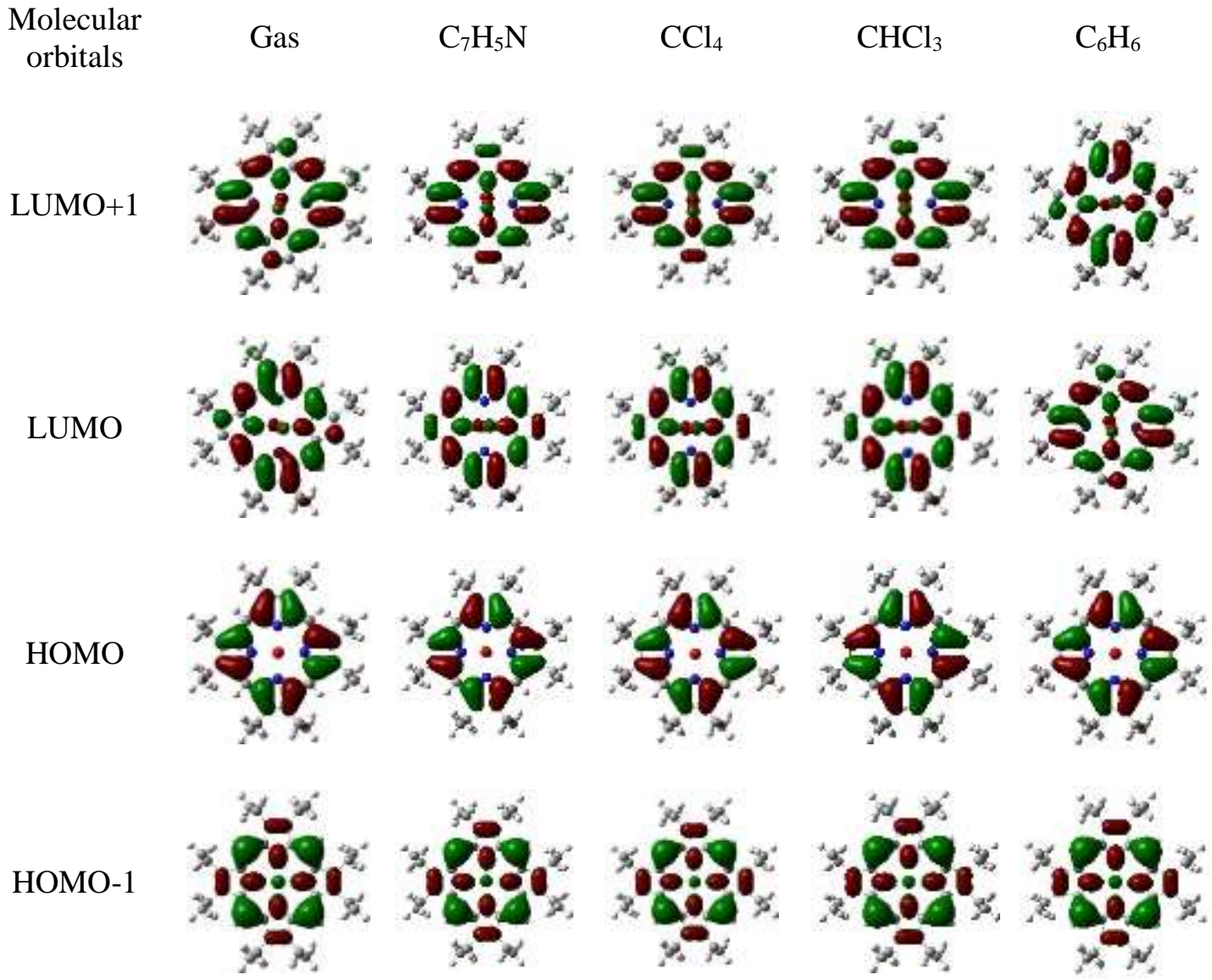

Figure 5. Molecular orbital's of(OEP)VO - isovalue of molecular density plot: 0.02

The analysis shows that, in gaseous and solvated phases, the dominant contribution in the HOMO-1 is located on vanadium, nitrogen atoms, the four methyl bridges and for the HOMO on the $\mathrm{C}-\mathrm{C}$ bonds of the pyrrole rings. About the representation of the molecular orbitals LUMO and LUMO+1, it can be noted that the first concerns two opposite nitrogen atoms while the second is located on the other two. These data suggest that the approach of the vanadyl ion on dianionic octaethylporphyrine will certainly be done in two stages: firstly, the overlap between the $p_{z}$ of two opposite nitrogen atoms with two d atomic orbitals of vanadium forming the first two bonds V-N and then in a second-time interaction to form the other two bonds

\section{Vibrational spectral analysis}

A vibrational analysis for (OEP)VO was performed in order to compare the harmonic frequencies determined at the DFT/B3LYP/6-31G(d) 
level and those recorded experimentally ${ }^{17}$. The IR spectra are shown in the following Figure.

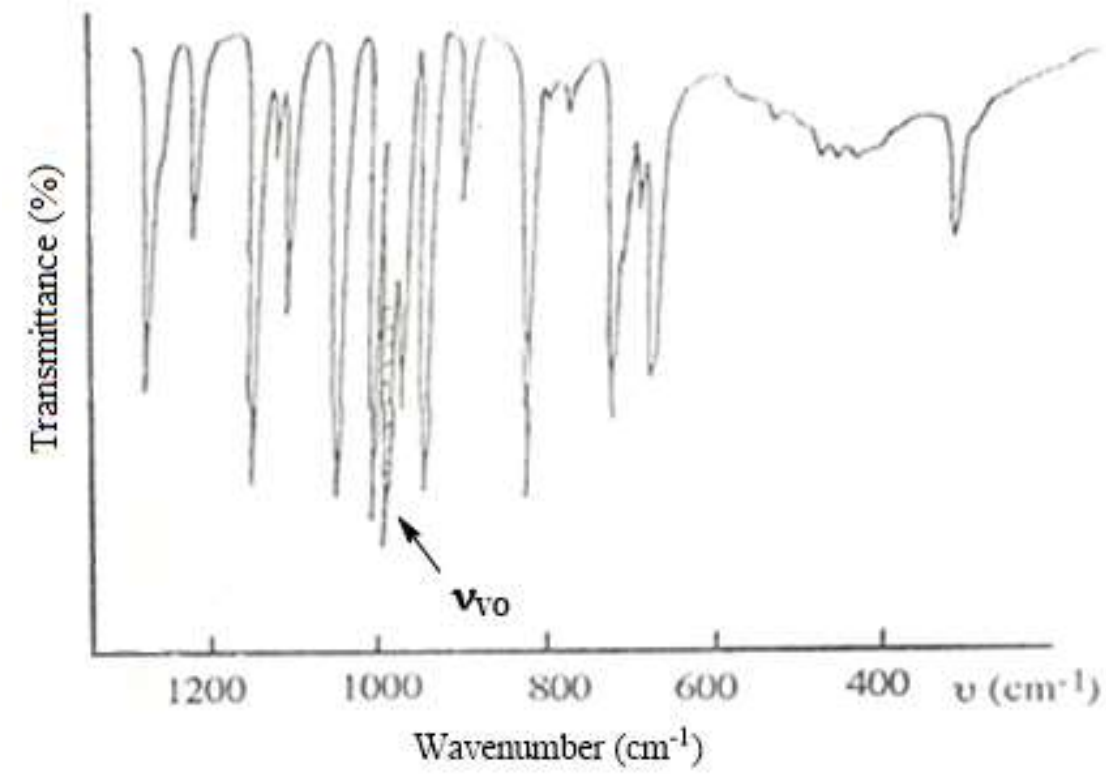

Wavenumber $\left(\mathrm{cm}^{-1}\right)$

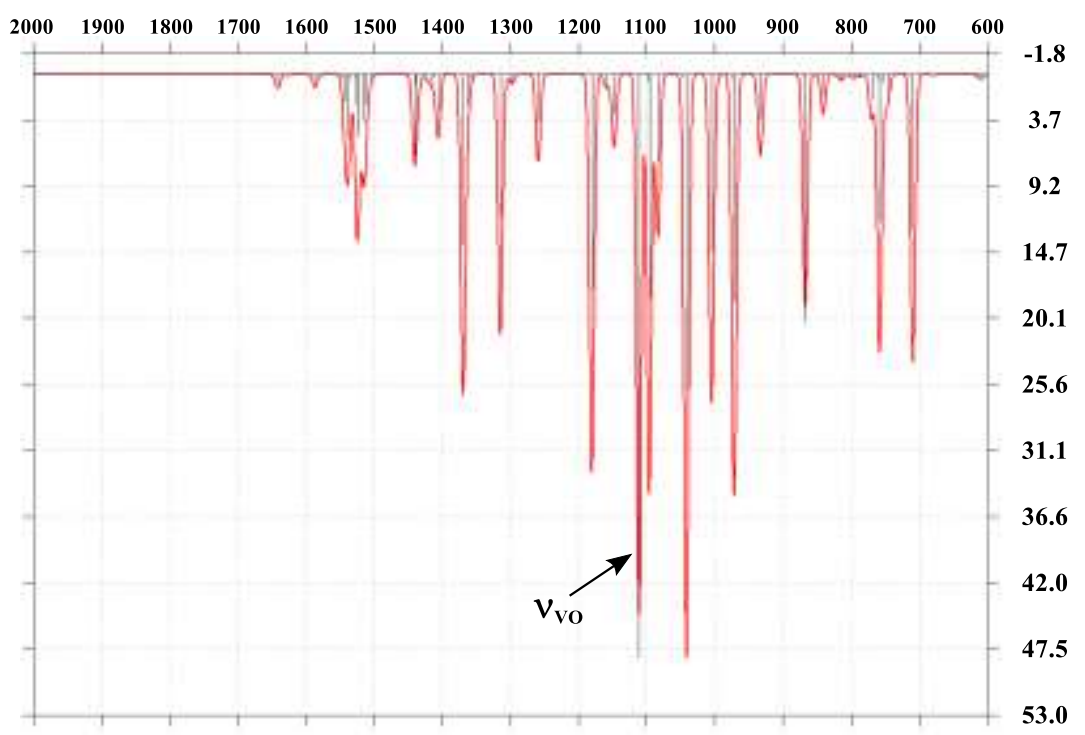

Figure 6. IR spectrum of (OEP)VO: Top - experimental, Bottom - calculated

In the region between $600 \mathrm{~cm}^{-1}$ and $2000 \mathrm{~cm}^{-1}$, the highest frequencies corresponding to the values 1640 $\mathrm{cm}^{-1}, 1260 \mathrm{~cm}^{-1}, 1110 \mathrm{~cm}^{-1}$ are associated respectively with the symmetrical stretching of $\mathrm{C}=\mathrm{C}$ in the pyrrolic ring, torsion of $\mathrm{CH}$ for methyl bridge and stretching of $\mathrm{V}=\mathrm{O}$ bond. Due to the electronic correlation, anharmonicity of the orbital bases used, the frequencies calculated using the DFT approach are generally higher than those obtained experimentally ${ }^{15}$. To overcome this, it is necessary to introduce a scale factor of the order of 0.9613 determined at B3LYP / 6-31G (d). Experimentally, only the frequency associated with the stretching of the $\mathrm{V}=\mathrm{O}$ bond has been reported $\left(1000 \mathrm{~cm}^{-1}\right)^{17}$, a value corresponding to that obtained $\left(1068 \mathrm{~cm}^{-1}\right)$.

\section{Conclusion}

In this work, the (OEP)VO complex was studied at the DFT / B3LYP / 6-31G (d) level. Structural analysis showed a square-based pyramidal geometry where the vanadyl group is at $0.54 \AA$ above the macrocycle plane. The distribution of the charge density determined the electron density isosurface where the electrons are spherically distributed in the center of the porphyrin macrocycle, certainly due to the electro-negativity of the oxygen atom. The infrared vibration frequencies of the fundamental modes were attributed and compared to the experiment. The existence of the four dative bonds between vanadium and nitrogen atoms could be identified by atomic charge calculations and by the 
analysis of the molecular orbitals of the two fragments $(\mathrm{OEP})^{2-}$ and $(\mathrm{VO})^{2+}$.

\section{Acknowledgements}

The authors thank AMCT for program Gaussian.

\section{References}

1- P. B. Tchounwou, C. G. Yedjou, A. K. Patlolla and D. J. Sutton, Heavy Metals Toxicity and the Environment, EXS, 2012, 101, 133-164.

2- B. Zhang, R. Qiu, L. Lu, X. Chen, C. He, J. Lu and Z. J. Ren, Autotrophic Vanadium(V) Bioreduction in Groundwater by Elemental Sulfur and Zerovalent Iron, Environ. Sci. Technol., 2018, 52, 7434-7442.

3- F. Abu-Awwad and P. Politzer, Variation of Parameters in Becke-3 Hybrid ExchangeCorrelation Functional, Journal of Computational Chemistry, 2000, 21, 227-238.

4- C. Lee and C. Sosa, Local density component of the Lee-Yang-Parr correlation energy functional, J. Chem. Phys., 1994, 100, 9018-9024.

5- M. J. Frisch, G. W. Trucks, H. B. Schlegel, G. E. Scuseria, M. A. Robb, J. R. Cheeseman, G. Scalmani, V. Barone, G. A. Petersson, H. Nakatsuji, X. Li, M. Caricato, A. Marenich, J. Bloino, B. G. Janesko, R. Gomperts, B. Mennucci, H. P. Hratchian, J. V. Ortiz, A. F. Izmaylov, J. L. Sonnenberg, D. WilliamsYoung, F. Ding, F. Lipparini, F. Egidi, J. Goings, B. Peng, A. Petrone, T. Henderson, D. Ranasinghe, V. G. Zakrzewski, J. Gao, N. Rega, G. Zheng, W. Liang, M. Hada, M. Ehara, K. Toyota, R. Fukuda, J. Hasegawa, M. Ishida, T. Nakajima, Y. Honda, O. Kitao, H. Nakai, T. Vreven, K. Throssell, J. A. Montgomery, Jr., J. E. Peralta, F. Ogliaro, M. Bearpark, J. J. Heyd, E. Brothers, K. N. Kudin, V. N. Staroverov, T. Keith, R. Kobayashi, J. Normand, K. Raghavachari, A. Rendell, J. C. Burant, S. S. Iyengar, J. Tomasi, M. Cossi, J. M. Millam, M. Klene, C. Adamo, R. Cammi, J. W. Ochterski, R. L. Martin, K. Morokuma, O. Farkas, J. B. Foresman, and D. J. Fox, Gaussian 09, Gaussian Inc, Wallingford CT, 2009.

6- A. E. Reed, L. A. Curtiss and F. Weinhold, Intermolecular interactions from a natural bond orbital, donor-acceptor viewpoint, Chem. Rev., 1988, 88, 899-926.

7- A. M. Köster, M. Leboeuf and D. Salahub, Molecular electrostatic potentials from density functional theory, Theoretical and Computational Chemistry, 1996, 3, 105-142.
8- R. Carbó-Dorca and P. Bultinck, Quantum Mechanical Basis for Mulliken Population Analysis, Journal of Mathematical Chemistry, 2004, 36, 231-239.

9- O. Tapia and O. Goscinski, Self-consistent Reaction Field Theory of Solvent Effects, Molecular Physics, 1975, 29, 1653-1661.

10- V. Barone, M. Cossi and J. Tomasi, A new definition of cavities for the computation of solvation free energies by the polarizable continuum model, J. Chem. Phys., 1997, 107, 3210-3221.

11- R. Dennington, T. Keith and J. Millam, Semichem. Inc., Shawnee Mission, KS, 2009.

12- M. G. B. Drew, P. C. H. Mitchell and C. E. Scott, Crystal and molecular structure of three oxovanadium (IV) porphyrins: oxovanadium tetraphenylporphyrin(I), oxovanadium (IV) etioporphyrin (II) and the 1:2 adduct of (II) with 1,4-dihydroxybenzene (III). Hydrogen bonding involving the VO group. Relevance to catalytic demetallisation, Inorganica Chimica Acta, 1984, 82, 63-68.

13- R. Salcedo, I. P. Zaragoza, J. M. MartínezMagadán and I. García-Cruz, Electronic structure in different environments for vanadyl porphyrinate molecules present in crude oil, Journal of Molecular Structure: THEOCHEM, 2003, 626, 195-201.

14- K. Yamashita, S. Tazawa and K. Sugiura, Oxo(porphyrinato)vanadium (IV) as a standard for geoporphyrins, Inorganica Chimica Acta, 2016, 439, 173-177.

15- G.V. Girichev, N.I. Giricheva, O.A. Golubchikov, Y.V. Mimenkov, A.S. Semeikind and S.A. Shlykov, Octamethylporphyrin copper, $\mathrm{C}_{28} \mathrm{H}_{28} \mathrm{~N}_{4} \mathrm{Cu}$ - A first experimental structure determination of porphyrins in gas phase, Journal of Molecular Structure, 2010, 978, 163-169.

16- G.V. Girichev, N.I. Giricheva, O.I. Koifman, Y.V. Minenkov, A.E. Pogonin, A.S. Semeikind and S.A. Shlykov, Molecular structure and bonding in octamethylporphyrintin(II), $\mathrm{SnN}_{4} \mathrm{C}_{28} \mathrm{H}_{28}$, Dalton Trans., 2012, 41, 7550-7558.

17- A.Zrineh., K.Bahja.M., Ferhat., J.M. Barbe, R.Guilard; Metal elements present in black phosphate minerals of Youssoufia (Morocco), characterization of vanadyl and nickel porphyrins [Éléments métalliques présents dans les phosphates noirs sableux de youssoufia (Maroc), caractérisation de porphyrines de vanadyle et de nickel], Analusis, 1995, 23(5), 222-224. 